\title{
Comentário II
}

\author{
Ana Maria Mauad
}

Depto. de História da Universidade Federal Fluminense

artigo apresentado por Ricardo Mendes levanta questões importantes para a elaboração de diretrizes políticas sobre os acervos fotográficos. A definição de um conjunto de questões que são colocadas diante do "desafio" digital não deve perder de vista que tal horizonte não está dado, envolvendo, necessariamente escolhas políticas. Tais escolhas revelam a existência de propostas diferenciadas para a organização dos acervos fotográficos e ao seu acesso cujo ponto-chave envolve a natureza pública ou privada de acervos. A forma de administrar os recursos disponibilizados para a gestão dos acervos terá nessa vocação inicial um ponto de variação significativa.

Nesse sentido, coloco que o horizonte digital para sair de uma virtualidade passiva, deve prioritariamente pautar-se em escolhas claras de como o acesso à informação será feito. Em paralelo, deverá também questionar-se sobre o fundamento epistemológico da produção continuada de informações visuais. Para que servem as imagens técnicas disponibilizadas em museus e institutos culturais, para conformar práticas de entretenimento ou produzir conhecimento crítico? E as imagens não disponibilizadas e guardadas em instituições cuja política de acesso é bastante limitada? Nesse caso como fica a busca de elementos para reconfigurações do passado já cristalizado em imagens repetidamente publicadas.

$\mathrm{Na}$ sua argumentação, Mendes enfatiza a problemática dos instrumentos de pesquisa e descritores formais, investigando como as diferentes instituições paulistas trataram dessa problemática. Sua preocupação revela-se quando reflete: "como os instrumentos de pesquisa na era digital poderiam restringir ou orientar - para o bem e para o mal - a produção documental e reflexiva, determinando as historiografias possíveis". Creio que essa preocupação vai ao encontro das minhas inquietações e farei então algumas considerações dentro desse campo. 
Desde 1996 quando passei a desenvolver um projeto de pesquisa junto ao CNPq, voltei-me para a avaliação das condições de pesquisa da fotografia no Rio de Janeiro. A primeira medida, nesse sentido, foi enumerar as instituições de guarda de material fotográfico e em seguida definir o acervo de cada uma dessas instituições.

projeto denominado o Poder em foco: a produção da fotografia pelo Estado brasileiro e a construção simbólica do Poder Político Republicano ( 1889 -1930) mapeou as instituições voltadas para a produção e guarda da imagem oficial. Segundo tal critério, nos detivemos na avaliação de cinco instituições: Museu da Imagem e do Som, Arquivo Geral da Cidade do Rio de Janeiro, Museu da República, Casa de Rui Barbosa e Arquivo Nacional. $\bigcirc$ resultado desse trabalho está disponibilizado na página do Laboratório de História Oral e Imagem (Labhoi), na publicação Oficinas da História - Nova Série, n. 1, (http://www.historia.uff.br/labhoi/ofic.htm)

Durante o segundo semestre de 2003, como desdobramento das atividades de pesquisa com acervos fotográficos, realizei com as pesquisadoras Solange Ferraz de Lima e Vânia Carvalho, do setor de Documentação do Museu Paulista, o meu projeto de pós-doutorado, no qual enfatizei a elaboração do registro. Tal ênfase explica-se porque ele tanto expressa uma interface com um pesquisador ideal quanto revela a forma como a fotografia está sendo concebida teórica e metodologicamente pela instituição de guarda.

Ao longo dos seis meses de pós-doutorado, tive a oportunidade de avaliar, em diferentes instituições de pesquisa e guarda de documentação histórica, a forma como as fotografias são tratadas em termos arquivísticos. Assim, minha preocupação concentrou-se no processo de indexação das fotografias como suporte de informações e representações, ou seja, parafraseando o historiador francês Jacques Le Goff, tanto como imagem-documento quanto imagem-monumento'.

Para o desenvolvimento de um estudo mais aprofundado escolhi as seguintes instituições: Arquivo Público do Estado do Rio de Janeiro, Biblioteca Nacional, Instituto Moreira Salles, e em Santiago do Chile, trabalhei com as pesquisadoras, da Dirección de Bibliotecas, Archivos y Museos (Dibam), Marcela Roubillar e Gloria Paz Nuñez, esta última coordenadora da seção de documentação e registro do Museu Histórico Nacional. A experiência da Dibam com o Sistema Unificado de Registro (SUR) possibilitou-me entrar em contato com uma realidade bem diferente da brasileira, na qual o modelo de gestão do patrimônio histórico, ao contrário do caso chileno, caracteriza-se pela descentralização.

Toda a pesquisa de campo teve no seu horizonte, com maior ou menor ênfase, a possibilidade de uma comparação com as experiências que estão sendo implementadas no Museu Paulista. Dessa forma, a avaliação da experiência 
do museu perpassa todas as demais, sendo tratada como referência para análise dos procedimentos adotados.

acervo Moreira Salles estrutura-se num total de 30 coleções, já incorporadas. O acervo é adquirido por doação e por compra, segundo um critério que valoriza alguns temas, dentre os quais o que mais se destaca é o da evolução da paisagem urbana. Dentre as grandes aquisições destacam-se as coleções de Gilberto Ferrez, neto do famoso fotógrafo Marc Ferrez, e a da Brascan, empresa pertencente ao Grupo Light. As coleções são tratadas como uma individualidade, a partir da qual se define um arranjo que pode ser temporal e/ou autoral. Muitas coleções já vêm com o arranjo pronto, como é o caso da coleção do fotógrafo francês Marcel Goutherot, organizada por estados e com os negativos já numerados - cerca de 22 mil imagens!

A localização topográfica da imagem é feita por uma codificação alfanumérica, em que cada fotografia possui uma identificação individualizada. $\bigcirc$ registro dos dados da imagem parte do thesaurus e adota-se um nível de vocabulário genérico. A indexação dos descritores obedece a uma hierarquia que é estabelecida pelo enfoque dado pela curadoria do acervo, nesse caso específico, a curadoria defende o princípio de que a fotografia é suporte de informação, pois por meio da imagem fotográfica é possível definir a presença de objetos, pessoas, lugares e construções.

registro das imagens fotográficas, no banco de dados, limita-se a indicar os objetos, pessoas, lugares, período e técnica/processo, utilizando-se para tanto descritores iconográficos definidos segundo um thesaurus ${ }^{2}$. Dentro das preocupações expressas pelo curador, em relação à possibilidade de descritores formais, destacou-se a necessidade de se avaliar o conjunto e de se estabelecer o objetivo da série, aplicando o conceito de obra autoral.

As fotografias no Arquivo Público do Estado do Rio de Janeiro estão sob a guarda da Divisão de Documentos Especiais (DDE), que além dessas inclui mapas e vídeos. A documentação fotográfica é composta pelos álbuns de fotografias que integram os diversos relatórios dos órgãos públicos do Estado, com ênfase para a década de 1930: o acervo da polícia política-Dops, a coleção de fotografias do movimento integralista e a coleção sobre o PCB, estas duas últimas já digitalizadas e disponibilizadas na rede interna do arquivo, por meio do banco de dados de base Access com as imagens em baixa resolução.

Para a organização das duas coleções digitalizadas foi aplicada a seguinte metodologia:

1. Notação individual (número para cada negativo).

2. Data.

3. Localização (cidade ou município).

4. Tema (assunto fotografado).

5. Descrição (detalhamento da imagem). A descrição será trabalhada com provas contatos no tamanho original dos negativos e imagem digital.
2. Dois exemplos bem-sucedidos de thesaurus são o Architectural and Arts Thesaurus (AAT), elaborado pela Getty Foudation, e o Iconclass, desenvolvi do peloWarburg Institute, ambos já podem ser consultados pela Internet nos respectivos sites: http:// www. getty.edu/art/collection e http://www iconclass. nl 
3.Além do SUR, o site do Patrimônio Fotográfico, entidade privada sem fins lucrativos, dirigida por Ilonka Schillag, é bastante interessante para uma avaliação do estado atual das questões em relação à conservação e catalogação de fotografia no Chile http://www.patrimoniofotografico.udp.cl/
É possível dentro do banco de dados realizar busca genérica por termos, no entanto a indexação da imagem - realizada no campo descrição limita-se aos aspectos da forma do conteúdo.

A Fundação Biblioteca Nacional concentra sua coleção de imagens na seção de Iconografia: mapas, aquarelas, gravuras e fotografias que estão organizadas em duas bases de dados: Iconografia, em que se pode acessar títulos e obras ilustradas, e Portal de Entrada de Dados Material Visual (DRDCAE), que engloba todas as imagens visuais em diversos tipos de suporte.

Na base denominada lconografia encontram-se 15 tipos de índices: autor-pessoas, autor-instituição, autor-eventos, títulos, assuntos, editores, ano da publicação, local da publicação, título das séries, classificação Dewey, topográfico, registro patrimonial, acervo digital, ISBN e notas bibliográficas.

Na base que organiza os materiais visuais, a ordem segue semelhante com uma leve mudança nas entradas: autor-pessoas, autor-instituição, autoreventos, títulos, assuntos, gênero/forma (tipo de suporte), editores/impressores, ano da publicação, título das séries, classificação Dewey, topográfico, registro patrimonial e acervo digital. Cada um dos índices possui uma listagem de termos em que a procura por meio de um instrumento de busca possibilita o acesso direto e a busca combinada, dentro dos limites dos termos já registrados.

Além do acervo visual, a biblioteca mantém o seu antigo catálogo, em que a entrada se faz por uma divisão entre obras publicadas, material visual, retratos e impressos. O registro de cada um segue a notação clássica das bibliotecas. Não há a mínima possibilidade de busca por descritores formais, somente por temas-assunto, ainda assim, existe um gap entre o que se encontra no arquivo antigo e o que está na base de dados informatizada.

O contato com a equipe chilena que projetou a idéia de um sistema integrado de registro, com indexadores icônicos e formais, foi realizado pela primeira vez, em 1997, durante o Io Encontro de História da Fotografia LatinoAmericana Gilberto Ferrez, organizado pela Funarte e realizado nos dias 27 e 28 de outubro de 1997, na Casa de Rui Barbosa/RJ. Nessa ocasião assisti à apresentação de Marcela Roubillar, que expôs o primeiro esboço de um banco de imagens que integrava os acervos de museus chilenos. Desde então, venho acompanhado o trabalho da equipe nas suas idas e vindas.

Atualmente o sistema está consolidado no programa SUR, o resultado de um trabalho conjunto do Centro de Documentação de Bens Patrimoniais (CDPB), entidade pertencente à Dibam, e Coinsa, órgão composto por especialistas em informática.

No momento o SUR está desenhado especialmente para a documentação de coleções dos museus, respondendo à necessidade de incorporar tecnologia ao trabalho museológico. A adoção dessa ferramenta segundo os seus administradores permite acessar a informação normalizada, de forma rápida e eficiente, melhorar a sua qualidade e consistência, proteger a longo prazo o valor da informação e agilizar seu intercâmbio e comunicação. A interface da base de registros na Internet pode ser acessada no endereço: http://www.surdoc.cli3. O SUR, tal como hoje pode ser acessado, perdeu o seu 
escopo original ganhando um nível de generalidade que, de acordo com a avaliação das pesquisadoras contatadas, não dá conta da especificidade regional e acaba por gerar conflito entre os diferentes tipos de museus. A questão maior se estabelece entre os museus de arqueologia, voltados para os períodos pré-hispânicos e para as culturas tradicionais, e os museus denominados históricos, guardiães da memória nacional e regional. Tal polêmica gerou a elaboração de dois thesauri, um para coleções museológicas e outro para arqueologia ${ }^{4}$.

Entre resistências e possibilidades

Tanto a reflexão de Mendes, sobre os acervos paulistas, quanto o relato das minhas experiências nos acervos cariocas e chileno, apontam para uma forte resistência ou ceticismo em relação à possibilidade de estabelecimento de um vocabulário adequado à natureza visual da fotografia, corroborando a conclusão tirada, anteriormente, pelas pesquisadoras do Museu Paulista:

Apesar dos avanços já empreendidos, os critérios de seleção e montagem das formas descritivas da imagem ainda deixam muito a desejar quando se trata de atender às necessidades de produção de conhecimento sobre a própria fotografia. A ausência de descritores voltados para os atributos formais da imagem é um dos problemas que merece destaque. $\bigcirc$ grau de estandardização dos termos descritivos do conteúdo visual deve levar em conta o perfil do público consulente, muitas vezes heterogêneo, e a tendência de integração das informações em redes internacionais. No entanto, não nos parece que a necessidade de descritores genéricos deva comprometer as particularidades das coleções institucionais, muito menos ignorar as expectativas do especialista ou os próprios atributos da fotografia ${ }^{5}$.

Creio que um dos caminhos para se superar resistências e impasses em relação aos acervos fotográficos, na era digital, é a elaboração de um canal ativo de troca de experiências, a partir do qual se compartilhe resultados e se consiga construir um ambiente comum. Um horizonte concreto, mesmo que virtual, em que os profissionais que se voltam para a análise crítica da imagem numérica (ou técnica) possam se encontrar, trocar idéias e compartilhar conhecimento.

Esse fórum já é uma boa iniciativa!
4. Ambos podem ser acessados pela Internet nos respectivos sites http:// www.tesauroregional.cl/ home_htm; para o arqueológico, e http://ww w.aatespanol.cl, para o de objetos gerais.

5.CARVALHO; L.IMA 2000 , p.24. 